\title{
Spatial mobility in elite academic institutions in economics: the case of Spain
}

\author{
Raquel Carrasco ${ }^{1}$ D Javier Ruiz-Castillo ${ }^{1}$
}

Received: 20 September 2018 / Accepted: 4 March 2019 / Published online: 12 March 2019

(c) The Author(s) 2019

\begin{abstract}
Using a dataset of 3540 economists working in 2007 in 125 of the best academic centers in 22 countries, this paper presents some evidence on spatial mobility patterns in Spain and other countries conditional on some personal, department, and country characteristics. There are productivity and other reasons for designing a scientific policy with the aims of attracting foreign talent (brain gain), minimizing the elite brain drain, and recovering nationals who have earned a Ph.D. or have spent some time abroad (brain circulation). Our main result is that Spain has more brain gain, more brain circulation and less brain drain than comparable large, continental European countries, i.e., Germany, France, and Italy, where economists have similar opportunities for publishing their research in English or in their own languages. We suggest that these results can be mostly explained by the governance changes introduced in a number of Spanish institutions in 1975-1990 by a sizable contingent of Spanish economists coming back home after attending graduate school abroad. These initiatives were also favored by the availability of resources to finance certain research-related activities, including international Ph.D. programs.
\end{abstract}

Keywords Governance · Economics institutions · Brain drain · Brain circulation · Brain gain

JEL Classification J61

Electronic supplementary material The online version of this article (https://doi.org/10.1007/s13209019-0189-5) contains supplementary material, which is available to authorized users.

Raquel Carrasco

rcarras@eco.uc3m.es

1 Departamento de Economía, Universidad Carlos III, Getafe, Spain 


\section{Introduction}

Using large bibliographic databases with information about the characteristics of documents appearing in the periodical literature, it has been established that, in all sciences, there is a heavy concentration of the most productive and influential researchers in top US research institutions. ${ }^{1}$ However, part of the success achieved by US institutions must be attributed to scholars born or having obtained a first college degree in other countries, giving rise to what Hunter et al. (2009) call the elite brain drain. ${ }^{2}$

This observation leads us to the subject matter of this paper, namely the role of geographic mobility in the organization of science. Specifically, we study the partition of researchers working in any country into three groups: (i) foreigners, or what we call brain gain; (ii) nationals who study and/or work abroad followed by a return to the home country, a phenomenon known as brain circulation; and (iii) nationals who study and work in their country of origin, or stayers. ${ }^{3}$ Yet, since the individual information on the country of origin and the place where one has studied or worked abroad is hard to collect, there are virtually no data that allow for consistent comparisons of mobility patterns across countries among the Ph.D. trained. In this paper, we study the spatial mobility of 3540 economists working in 2007 in 125 economics departments and research centers in 22 countries. These 125 centers are selected among the best in each country according to the Econphd (2004) ranking of institutions and other considerations (see Sect. 2.1 on the selection of sample countries and departments).

The following three characteristics should be emphasized at the outset. Firstly, $51.8 \%$ of the sample consists of movers $(34.4 \%$ of brain gain and $27.4 \%$ of brain circulation). Secondly, more than three quarters of all immigrants are concentrated in a few countries: $53.4 \%$ in the USA and $26 \%$ in what we call open countries (Canada, the UK, Australia, and Switzerland). Thirdly, a number of continental European countries, which we call closed countries, are characterized by a small percentage of brain gain and a large percentage of stayers (Germany, France, Italy, Netherlands, Belgium,

\footnotetext{
1 See inter alia Batty (2003), Dosi et al. (2006), Albarrán et al. (2010, 2011), Herranz and Ruiz-Castillo (2013), Rodriguez-Navarro (2016), Bonaccorsi et al. (2017a), Rodriguez-Navarro and Brito (2018a, b). Yearly rankings using the volume and citation impact of publications can be obtained, among others, from the following two sources: the Leiden Ranking (www.leidenranking.com), a bibliometric ranking of universities based on the Web of Science, presently distributed by Clarivate Analytics, and the SCImago Institutions Rankings (SIR; www.scimagoir.com), a bibliometric ranking of research institutions based on the Scopus database, distributed by Elsevier.

2 For the economics of immigration, see Borjas (1999), Stark (2005), McDowell and Singell (2000), and Franzoni et al. (2014, 2015), and for a survey of four decades of economics research on the brain drain, see Doquier and Rapoport (2012). Specifically, for the importance of foreigners in US science, see Section 2 in Doquier and Rapoport (2012) and chapter 8 in Stephan (2012); for the elite brain drain, see Stephan and Levin (2001), Laudel (2003, 2005), Basu (2006), Bauwens et al. (2008), Parker et al. (2010), Parey et al. (2017), and Albarrán et al. (2017a, b).

3 Just as immigrants are said to be brain drained from the point of view of sending countries, in this paper immigrants are said to be brain gained from the point of view of receiving countries. This use is at variance with the "new economics of brain drain" (see inter alia Stark 2005), where brain gain refers to the idea that the prospect of migration provides incentives to individuals in the sending countries to build the greatest possible stock in human capital.
} 
Sweden, and Denmark). ${ }^{4}$ In this scenario, we focus on a comparison of Spain and Germany, France, and Italy. These are four large, demographically comparable continental members of the European Union, and non-English-speaking countries where economists have similar opportunities for publishing their research in English or in their own languages.

It turns out that Spain has more brain gain, more brain circulation, and less brain drain than Germany, France, and Italy. However, this unconditional evidence must be subject to as many controls as possible. The reason, of course, is that the probability that an individual becomes an immigrant may depend on her individual characteristics, the relative attractiveness of the department where she works, as well as the characteristics of the countries of origin and destination. Our main finding is that our descriptive results are maintained after controlling for demographic variables, Ph.D. education, a measure of individual productivity, average department productivity, and per capita GDP. This is important because, in the context of increased global competition for skilled workers (OECD 2008; Freeman 2010; Jacob and Meek 2013; Geuna 2015), any country has reasons for designing a scientific policy with the aims of attracting foreign talent (brain gain), minimizing the elite brain drain, and recovering nationals who have earned a Ph.D. or have spent some time abroad (brain circulation).

A relevant aspect is whether the productivity of brain gain and those who return from abroad to work in their country of origin differs from the productivity of those who study and work in the country in question. As is well known, an answer to these questions should consider that the unobservable ability of individuals is correlated both with migration and with performance. The results of the literature and the correlations observed in our sample indicate that the productivity of foreigners is greater than or equal to the productivity of stayers (McDowell and Singell 2000; Stephan and Levin 2001; Hunter et al. 2009; Franzoni et al. 2014; Albarrán et al. 2017b). Moreover, among the nationals from any country, the productivity of scientists that have been brain drained in the top US departments is generally greater than the productivity of those in brain circulation, while the productivity of the latter is greater than the productivity of stayers (see Sect. 4). In addition, from the point of view of the sending countries, there are other reasons for concern about the consequences of the brain drain. As Laudel (2005) has emphasized for narrowly defined specialties, the consequences for any country from losing elite members typically mean that the national specialty becomes uncoupled from frontier science; quality standards might no longer be enforced nationally; the country may no longer be able to recruit or train the best young scientists in the field (a country needs elites to generate elites); and an important channel for communicating societal interests to those who govern the specialty is lost.

\footnotetext{
4 These features are not exclusive to economics. In particular, the partition into the US, open, closed, and other countries is similar to the one in the largest dataset in the literature (Franzoni et al. 2015), consisting of 17,182 researchers in biology, chemistry, materials science, and earth and environmental science working in 2011 in 16 'core' countries, 14 of which coincide with some of our 22 countries. The importance of mobility and the concentration of brain drain in a few countries in these sciences are of a similar order of magnitude to what we found in economics (for the details of these comparisons, see Sect. 3.3).
} 
On the other hand, it can be argued that geographic mobility is beneficial to receiving countries because (i) mobile scientists place themselves in settings where they can be more productive due to specialized skills or equipment that exists only in specific locations (Jones 2008; Stephan 2012), (ii) both foreign-born scientists and returnees have larger international research networks than do native researchers who lack an international background (Scellato et al. 2015), and (iii) a more diverse knowledge or ethnic mix boosts creative outcomes (Freeman and Huang 2015). Finally, as pointed out by Velema (2012), scientists in brain circulation can contribute to the national science system in several ways, such as facilitating access to foreign resources, improving the reputation and international profile of their country of origin, enhancing the international orientation of colleagues or students in the local scientific community, and contributing to the creation of an institutional environment in which science and research can prosper.

It should be noted that, in comparison with other sciences, the ability of Spanish institutions in economics to attract immigrants constitutes an exception: The percentage of brain gain in Spain is $31.1 \%$ in our sample but only $7.3 \%$ in the four sciences studied by Franzoni et al. (2015). Thus, the question addressed in this paper is how to explain the differences in this respect between Spain and other comparable European countries. Given the set of individual, departmental, and country characteristics we control for, a significant difference between the effect of Spain and other countries on the probability of becoming an immigrant must be attributed to uncontrolled variables. In our suggested interpretation, the most important uncontrolled variables refer to governance. Our reasoning is the following. Higher education in the four large European countries emphasized in this paper is dominated by an old public system repeatedly criticized in the literature for being relatively closed to foreign competition and because research does not necessarily hold a predominant place (see inter alia Portes 1987; Frey and Eichenberger 1993; Bonaccorsi 2007). However, the Spanish situation in economics changed dramatically during the sample period. Since the mid-1970s, a sizable contingent of brain circulation economists has made a number of drastic changes in the Spanish centers in our dataset compatible with the rules for becoming a public servant in the official system. These governance changes include: (i) the introduction of meritocratic hiring and promotion rules with the aim of fomenting quality research; (ii) a strong international Ph.D. program; and (iii) the use of English as the working language. On the contrary, with few exceptions, the governance of the institutions in the other countries has remained largely unchanged during the period. Thus, we mainly attribute our results on country effects to the unobservable governance changes in Spain. A second unobservable factor that may have a role in the results is the increase in resources for research-related activities in Spain since the mid-1980s coming from two sources: public higher education budgets, and Spanish and European Union competitive grants. ${ }^{5}$

In order to understand the policy implications of our analysis, consider the following two points. Firstly, the increase in resources for research facilities in Spain benefited

\footnotetext{
5 The improvement of Spanish economics institutions in international research rankings during the same period, which has been documented elsewhere (Drèze and Estevan 2007; Ruiz-Castillo 2008), has also been attributed to these governance changes in elite Spanish centers and the availability of increased resources for research.
} 
all sciences. However, differences in mobility patterns between Spain and comparable European countries have only taken place in economics. Secondly, the government changes emphasized in our interpretation are not the consequences of a new policy at the national or university levels, but the result of decisions taken by a self-selected number of institutions in economics. Thus, in the context of a rigid system of higher education in continental Europe that does not have at its core the promotion of quality research, our results indicate that initiatives at a local level in a given science can have measurable consequences on international mobility patterns.

The remainder of this article is organized as follows. Section 2 describes the data, Sect. 3 presents descriptive statistics, including a useful partition of the 22 sample countries into five types, while Sect. 4 discusses our correlations on productivity comparisons. Section 5 presents the empirical model and the estimation results on the probability that an individual becomes an immigrant, Sect. 6 discusses them, and Sect. 7 concludes. In order to facilitate the reading of the text, Supplementary Material document contains some additional information on the construction of the dataset, other descriptive statistics, and some empirical results.

\section{The dataset}

\subsection{The selection of sample countries and departments}

It must be recognized that, beyond the first 50 or 70 positions, any international ranking becomes very much open to debate. Nevertheless, any acceptable ranking may be safely used for the mere selection of a representative sample of the best institutions in any country, regardless of whether the exact rank received by a given institution actually represents its true place in the world. In our case, research excellence is generally assessed in terms of the Econphd (2004) ranking. ${ }^{6}$

We select countries and departments in four steps. ${ }^{7}$ We begin with a dataset used in previous contributions (Carrasco and Ruiz-Castillo 2014; Albarrán et al. 2017a, b), consisting of the top 81 Economics departments worldwide according to the Econphd (2004) ranking. We aim to select a minimum of five or six departments for large European countries and important cases, such as Canada, and a minimum of two departments for any other country. With this criterion, we find that the following five countries are well represented in the original sample (with the number of departments in brackets): the USA (52), the UK (8), the Netherlands (4), Sweden (2), and Israel (2). In the second step, in the remaining seven countries with at least one department in the original list, we add 17 institutions as follows (with the total number in brackets): five in Germany (6), four in France (5), three in Spain (6), two in Belgium (3), and one in Canada (5), Denmark (2), and China (2). In the third step, we use information on the institutions between the 81 and the 125 th position in the Econphd

\footnotetext{
6 This ranking takes into account the publications in the period 1993-2003 in the top 63 economics journals in the Kalaitzidakis et al. (2003) weighted journal ranking, where the weights reflect journal citation counts adjusted for factors such as the annual number of pages and the age of the journal (for further methodological details, see Econphd 2004).

7 To save space, details and some exceptions are discussed in Section SM1 in Supplementary Material.
} 
(2004) ranking. Among the new countries with at least one department in this interval, we include the following three (with the number of departments in brackets): Italy (5), whose Università Bocconi occupies the 101 position; Australia (2), whose first three universities are ranked in this interval; and Switzerland (2), whose University of Zürich occupies the 99th position. Finally, for the sake of completeness, we add the following seven countries whose best departments do not appear within the first 125 positions in the Econphd (2004) ranking: Greece (2) and Portugal (2) are included to complete the vision offered by other small members of the European Union that are considerably more affluent; we also include Turkey (4), a country geographically close to the European Union but with a different culture and with a number of prominent nationals among the elite in economics; finally, we find it interesting to include four countries in Central and South America: three Spanish-speaking countries-Mexico (4), Argentina (2), and Chile (2)—plus Brazil (3). As we will see, the inclusion of these countries with 19 departments has been worthwhile.

The final dataset includes 125 university departments and research centers in 22 countries. The list of institutions in each country, ordered by their Econphd rank, is given in Table A in Section SM1 in Supplementary Material. In spite of the difficulties and shortcomings recognized in that section, we have constructed a sound sample of the most productive institutions in 2007 in an interesting list of countries.

\subsection{Collecting individual information, and the distribution of researchers by institutions in each country}

In most centers, we searched for individual researchers in the departmental Web pages in 2007. The minimum information we require for each individual includes the nationality, the university where a Ph.D. is obtained, the age, the gender, and the publications in the periodical literature up to 2007. There are 3540 individuals in the dataset with at least one publication and with complete information on education and age. The distribution of these individuals by institutions in each country is presented in Table A in Section SM1 in Supplementary Material. Details on how we collected individual information, as well as the distribution of institutions by size in each country, are discussed in Section SM2 in Supplementary Material. As we conclude in that section, the greatest difficulty might relate to the quality of our information on stayers and hence on the total number of economists working in 2007 or originating in a given country. For example, if we are unable to include all junior stayers in German institutions, then our estimate of the percentage of brain gain, brain drain, and net gain over the sum of brain circulation and stayers in Germany will be biased upward. The opposite will be the case if we have too many stayers in some French or Italian universities.

\subsection{The measurement of individual productivity}

Because of budgetary restrictions, our information on productivity suffers from two limitations: We make no distinction between single and multiple authorship in each publication and we do not consider the citation impact achieved by every article. What we do is to construct a quality index that weights differently the publications 
each individual has over her academic career up to 2007 in four journal classes. ${ }^{8} \mathrm{We}$ believe that, to stress the difference between top and local journals, it is desirable to value class A journals very highly. We should also recognize the role of excellent field journals. Thus, the four classes are assigned weights equal to 40,15, 7, and 1 point, respectively. The resulting quality index is denoted by $Q .{ }^{9}$ The mean $Q$ for all centers is presented in Table A in Section SM1 in Supplementary Material.

\section{Descriptive statistics on spatial mobility}

\subsection{Mobility variables}

Our information concerning mobility patterns is limited but interesting. We only know the country where individuals earn a B.A. or a Ph.D. and the country where they work in 2007. Therefore, any move that takes place during the period between obtaining a Ph.D. and 2007 is ignored. This means that we cannot separate permanent migration from temporary mobility. Nevertheless, among the 3540 economists working in 2007 in any of the 22 sample countries, we can distinguish between: (i) those who have completed all their studies in the country in question (stayers); (ii) those who study their Ph.D. abroad but come back to the country of origin (brain circulation); and (iii) those born in any other country in the world (brain gain). In turn, the 3253 economists born in the 22 countries in the dataset can be partitioned into stayers, brain circulation, and those who work in 2007 in a different country than the one where they originate (brain drain). Note that there are $3540-3253=287$ economists born outside our sample countries that are part of the brain gain in these 22 countries. The quality of our information on mobility variables is defended in Section SM4 in Supplementary Material.

\subsection{Country types}

As we will presently see, it is convenient to classify the 22 sample countries into five well-defined types. For that purpose, Fig. 1 illustrates the partition of the economists working in 2007 in any country into brain gain, brain circulation, and stayers. (The numerical information is given in Table B in Section SM4 in Supplementary Material.)

\footnotetext{
8 Classes A, B, and C consist of 5, 34, and 47 journals, respectively, while class D consists of any other journal. Class A includes the American Economic Review, Econometrica, Journal of Political Economy, Quarterly Journal of Economics, and Review of Economic Studies. By way of example, the following 12 journals are in class B: Economic Journal, Games and Economic Behavior, International Economic Review, Journal of Econometrics, Journal of Economic Growth, Journal of Economic Theory, Journal of Finance, Journal of Labor Economics, Journal of Monetary Economics, Journal of Public Economics, Rand Journal of Economics, and Review of Economics and Statistics. See Appendix II in Albarrán et al. (2014) for the listing of all journals in classes B and C.

9 This index has been used in our previous publications (Albarrán et al. 2017a, b, as well as Carrasco and Ruiz-Castillo 2014). To save space, for further details concerning this construction see Section SM3 in Supplementary Material.
} 


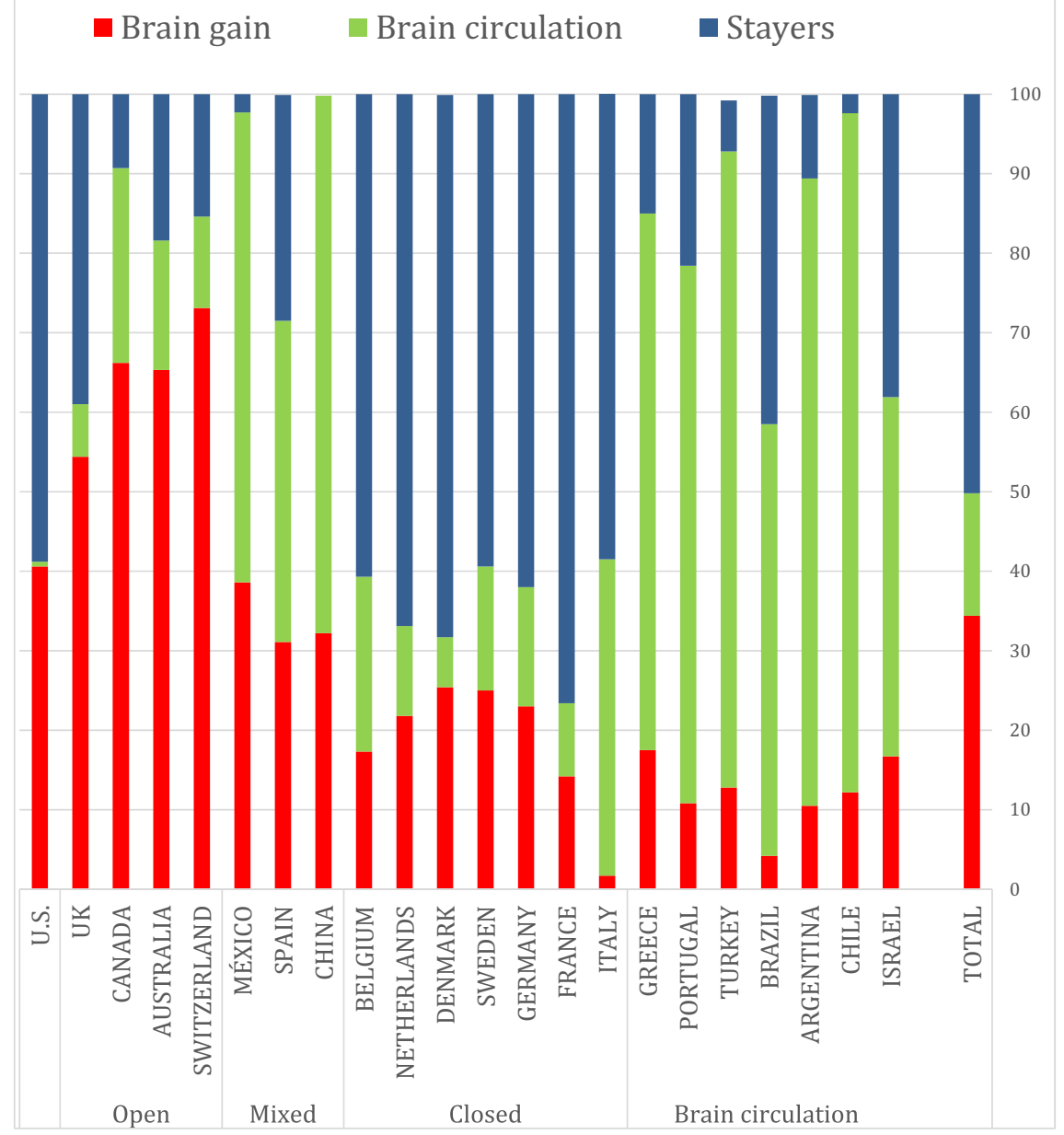

Fig. 1 Partition of individuals working in 2007 in each country into brain gain, brain circulation, and stayers

We begin by noting that the 14 countries in the right-hand side of Fig. 1 have below average percentages of brain gain (in red). These countries can be partitioned into two types. Firstly, Netherlands, Belgium, Sweden, Denmark, Germany, and France are also characterized by a relatively low percentage of brain circulation and, therefore, a large proportion of stayers (in blue), ranging from $59.4 \%$ of the total number working in Sweden to $76.6 \%$ in France. Italy, with the lowest percentage of brain gain, has also a high percentage of stayers. Consequently, we refer to these seven European countries as closed countries. Secondly, many of the best B.A. graduates in a number of countries with weak graduate schools choose to earn a Ph.D. abroad, mainly in the USA. After this investment in human capital, these foreign Ph.Ds. are welcome back home to work in the best economics departments. In our dataset, Greece, Portugal, 
Turkey, Brazil, Argentina, Chile, and Israel, with a very high proportion of brain circulation (in green) and a below average proportion of stayers, are referred to as brain circulation countries.

The remaining eight countries in the left-hand side of Fig. 1, all of which have a relatively large proportion of brain gain, will be classified into three types. Firstly, the USA, with a negligible proportion of brain circulation and a proportion of stayers around the sample average, constitutes a special case better treated separately. Secondly, in the UK, Canada, Australia, and Switzerland, with the highest proportion of brain gain, the number of foreigners is greater than the number of nationals working there. Thus, we refer to them as open countries. Finally, Mexico, Spain, and China form a mixed type. Their proportion of brain gain, around the sample average, places them close to the open countries and away from brain circulation and closed countries. But their proportion of brain circulation, well above average, makes them quite different from open and closed countries.

The following two points should be emphasized. Firstly, the fact that $79.3 \%$ of all brain drained economists work either on the USA or the four open countries clearly indicates that it is very hard to attract foreigners away from the USA, the other three Anglo-Saxon countries, and Switzerland. Thus, only $13.9 \%$ of the brain gain total works in the 14 closed and brain circulation countries. The remaining $6.8 \%$ immigrants work in Spain, Mexico, and China. Secondly, judging from its brain circulation percentage, Spain and Italy are closer to Portugal and Greece than to the remaining six continental members of the European Union in our sample. Thus, descriptive statistics seem to indicate that these four Southern European countries could be classified as brain circulation countries. More recently, however, whereas Italy has become a closed country with a large percentage of stayers, Spain has surprisingly become an open country. Mexico and China seem to have traversed a similar route from brain circulation to open countries.

It is also interesting to consider the partition of the economists born in each of the sample countries into brain drain, brain circulation, and stayers. As given in Table C in Section SM4 in Supplementary Material, the proportion of brain drain does not generally follow a regular pattern by country type. In spite of this variability, it is worthwhile to compare the size of the brain gain and brain drain flows in each country. Of course, the number of individuals born in a country need not be equal to the number of economists working there in 2007. However, we can compare the flows of brain gain and brain drain as a percentage of the nationals working in each country, that is, the sum of brain circulation and stayers in each country. We define the percentage of net gain as the difference between the percentages of brain gain and brain drain over this denominator (Table D in Section SM3 in Supplementary Material). The situation is illustrated in Fig. 2. The results are very eloquent. Firstly, except Netherlands, all closed and brain circulation countries have a negative percentage of net gain. Secondly, the USA, open and mixed countries, except China, with a large percentage of brain drain, have a positive percentage of net gain. 


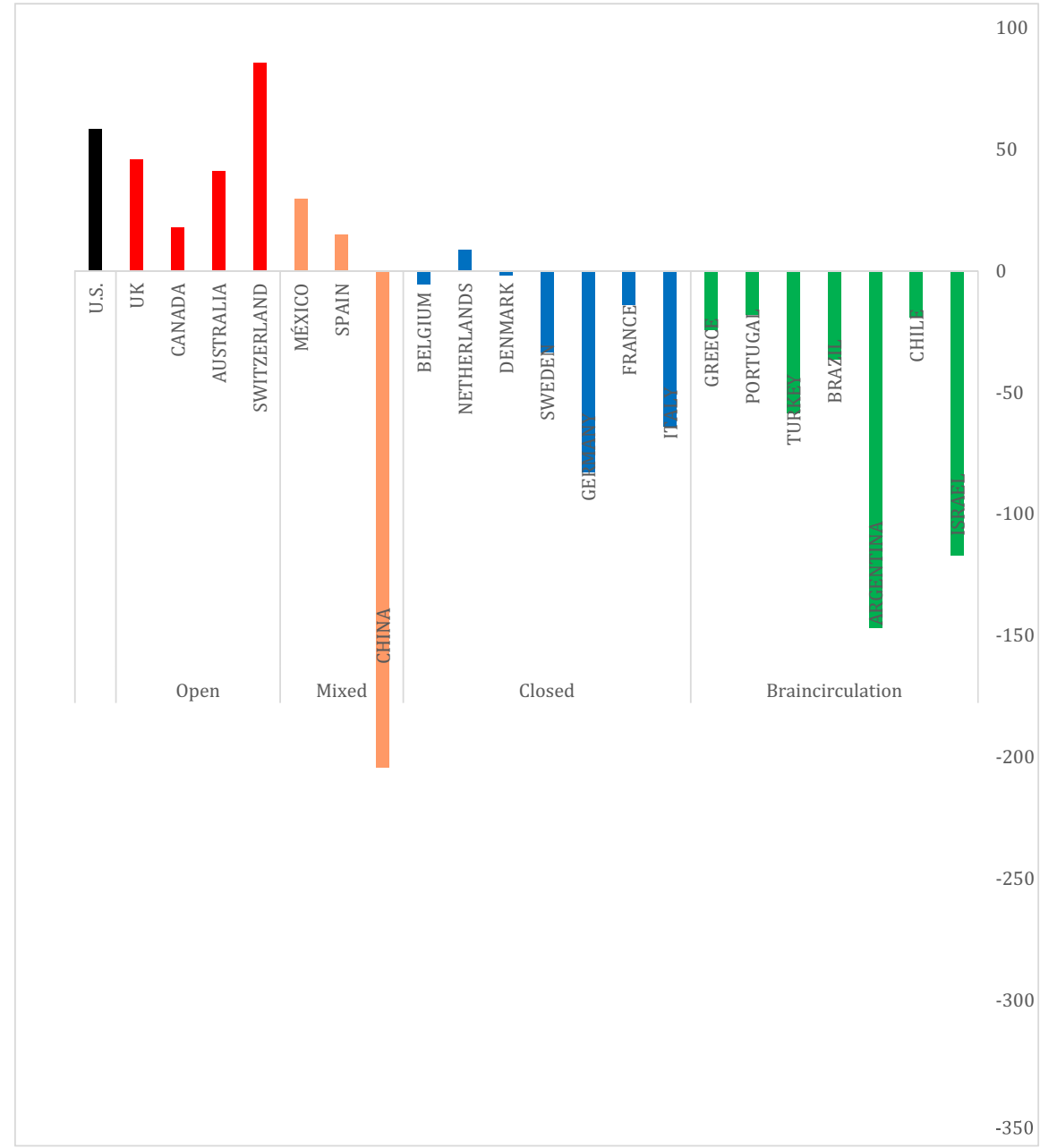

Fig. 2 Countries classified according to the percentage of net gain over the nationals (brain circulation + stayers) working in each country

\subsection{A comparison with other sciences}

It is interesting to compare the above descriptive statistics with the corresponding information for other sciences. Unfortunately, the study of geographic mobility using large datasets is limited at present to a definition of mobile researchers as those who change affiliations during a reduced time period. However, we know of two other contributions comparable to our own. For space reasons, we report briefly about the most important one from Franzoni et al. (2015) (for a detailed discussion, see Section SM5 in Supplementary Material).

These authors collect information-albeit in a roundabout way-for 17,182 researchers in four scientific fields: biology, chemistry, materials science, and earth 
and environmental sciences. Geographic mobility patterns in these sciences are similar to our own in two respects. Firstly, as indicated in note 4, the partition into the USA, open, closed, and other countries among 16 "core" countries, 14 of which coincide with some of our 22 countries, is similar to the one in economics. The only difference is that, together with the UK, Canada, Australia, and Switzerland, Sweden is included among the open countries. Secondly, out of the total number of researchers, $53.4 \%$ are movers-24.0\% foreign-born, and $29.4 \%$ returnees - a percentage comparable with the $49.4 \%$ in our sample. Similarly, there is a concentration of immigrants into a few countries of the same order of magnitude as our own: $42.0 \%$ work or study in the USA and $34.4 \%$ in open countries. ${ }^{10}$

However, there is a key difference worth emphasizing: While the percentage of brain gain in Spain is $31.1 \%$ in our sample, it is only $7.3 \%$ in Franzoni et al. (2015). The conclusion is that, in comparison with other European countries, the Spanish case in economics constitutes an exception in need of an explanation.

\section{Productivity comparisons}

We are concerned with the following two issues.

1. What is the contribution of immigrants to the average productivity of the country where they work? To answer this question, we compare the average productivity of foreigners, brain circulation, and stayers in each country.

2. Among all researchers born in a given country, we would like to investigate whether those brain drained are more productive than stayers. For completeness, we are also interested in comparing the productivity of brain circulation and brain drained economists.

To answer these questions, we use regressions of individual productivity on a number of mobility, individual, and department characteristics. Among personal control variables, we have information on years of academic experience, gender, and the university where individuals earn their first college degree and where they attend graduate school. In previous research, we have documented the importance of department effects in the sense that when we partition departments into several categories according to their prestige - say, top, intermediate, and bottom categories - the average productivity of economists working in each category is hierarchically ordered (Albarrán et al. 2017b). Using the Econphd (2004) department ranking, we distinguish between five categories. The 52 US departments are partitioned into the Top 25 and the Next 27. The 73 non-US departments are partitioned into the Top 15, the Bottom 43, and the Last 15 belonging to the brain circulation countries except Israel. ${ }^{11}$

\footnotetext{
10 In the only additional dataset we know of, consisting of the 317 highly cited mathematicians studied in Panaretos and Malesios (2012), the importance of movers and the concentration of brain gain in the USA are of a similar order of magnitude.

11 Of course, which departments are at any moment in the "top 25" or "bottom 27" in the USA, or the "top 15 ," "bottom 43," and the last 15 outside the USA is open to debate. Moreover, even if this classification is appropriate for the period 2004-2007, individual departments are likely to have changed positions over the period of this study prior to 2007. Therefore, it is advisable to take this partition as representative of "top" or "bottom" departments in general.
} 
Table 1 Productivity comparisons between foreigners, brain circulation, and stayers working in all countries

A. Results within the five department categories
Top 25 US departments
Foreigners $\approx$ brain circulation $\approx$ stayers
Top 15 non-US departments
Next 27 US departments
Brain circulation $>$ foreigners $>$ stayers

Bottom 43 non-US departments

Last 15 non-US departments in brain circulation countries

Foreigners $\approx$ brain circulation $>$ stayers except Israel (Portugal, Greece, Turkey, Brazil, Argentina, Chile)

B. Results within specific countries

\begin{tabular}{ll}
$\begin{array}{l}\text { Mexico } \\
\text { Top } 25 \text { USA }\end{array}$ & $\begin{array}{l}\text { Foreigners }>\text { brain circulation and stayers } \\
\text { UK }\end{array}$ \\
Fanada & \\
$\begin{array}{l}\text { Frael } \\
\text { Australia/Switzerland }\end{array}$ & Foreigners $\approx$ brain circulation $\approx$ stayers \\
$\begin{array}{l}\text { Germany } \\
\text { Belgium }\end{array}$ & \\
$\begin{array}{l}\text { Denmark/Sweden } \\
\text { Portugal, Greece, Turkey, Brazil, Argentina, Chile }\end{array}$ & \\
$\begin{array}{l}\text { Next } 27 \text { US departments } \\
\text { France }\end{array}$ & Brain circulation $>$ foreigners $>$ stayers \\
$\begin{array}{l}\text { Spain } \\
\text { China (there are no stayers) }\end{array}$ & \\
Netherlands & Brain circulation $>$ foreigners \\
\hline
\end{tabular}

It should be emphasized at the outset that, since we do not have information for dealing with the endogeneity of mobility choices, we can only report correlations. Nevertheless, our correlation results will describe the productivity characteristics of our sample. To save space, we relegate the regression analysis to Section SM6 in Supplementary Material. Here, we merely report the key results.

(1) The results in the literature concerning the existence of productivity differences between immigrants and nationals are mixed. Our results indicate that, controlling for personal characteristics and fixed department effects, foreigners are more productive than brain circulation, and the latter are more productive than stayers (Table $\mathrm{H}$ in Section SM6). ${ }^{12}$ However, when we make productivity comparisons between immigrants and stayers within department categories, the situation is different in top and bottom institutions. Results are summarized in Panel A in Table 1 (from Table I in SM6). We also study the effect of these mobility variables in each country (or aggregates of countries when required by data limitations). Results are summarized in Panel B in Table 1 (from Table J in SM6).

\footnotetext{
$\overline{12} p$ values for these and the remaining productivity comparisons in this section are available on request. 
Table 2 Productivity comparisons between brain drain, brain circulation, and stayers among economists born in all countries

\begin{tabular}{ll}
\hline UK, Sweden/Denmark & Brain drain in the Top 25 US departments $>$ stayers \\
$\begin{array}{l}\text { Spain, Germany, France, Italy, Italy, Belgium, } \\
\text { Australia/Switzerland }\end{array}$ & Brain drain in All other departments $>$ stayers \\
Chine, Portugal, Greece, Turkey, Brazil, & \\
Argentina, Chile & \\
Canada, Netherlands, Israel & Brain drain in the Top 25 US departments < stayers \\
USA & Brain drain < stayers in the Top 25 US departments \\
\hline
\end{tabular}

Two points are in order. Firstly, in the USA we confirm that, as in Albarrán et al. (2017b), the productivity of foreigners and stayers is indistinguishable at the top, while foreigners are more productive than stayers at the bottom. The novelty in Panel A is that this situation is essentially reproduced outside the USA: Foreigners and stayers in the Top 15 departments are equally productive, whereas immigrants are more productive than stayers in both the Bottom 43 and the Last 15 departments. In Panel B, the situation at the top is represented by the Top 25 US departments, the UK, Canada, and Israel. Except in Netherlands, in all other countries foreigners are more productive than stayers. Note that the stayers in our sample of top institutions are presumably more productive than the rest of stayers in any country. Therefore, suppose that the brain gain in any country is reduced by half. Since the replacement must come from the pool of country stayers, the result will surely be detrimental to the country in question.

Secondly, the situation of brain circulation economists is remarkable: Except in Mexico, they are as productive or even more productive than foreigners. Thus, except at the top department and countries where foreigners, brain circulation, and stayers are indistinguishable, the productivity of brain circulation is greater than the productivity of stayers.

(2) Ideally, for all economists born in a given country, we would like to compare the average productivity of three types of individuals: brain drain, brain circulation, and stayers. If possible, we would like to differentiate between brain drained economists in different department categories. Because of data limitations, we can separate brain drained individuals at most into two groups: those working in Top 25 US departments, and those working in what we call All other departments, namely the sum of the Next 27 US departments plus the 73 non-US departments. Results are summarized in Table 2 (from Table K in SM6).

Unsurprisingly, in 16 countries the productivity of brained drained economists is greater than the productivity of stayers, while there are three countries for which the productivity of stayers is so high that it is indistinguishable from the productivity of those brain drained even in the Top 25 US departments: Israel, Canada, and Netherlands. ${ }^{13}$ Finally, the USA constitute an exception in which brain drain economists

\footnotetext{
13 Since Mexican brain circulation and stayers are treated together and there are no Chinese stayers, this issue does not apply to these countries.
} 
appear to be negatively selected relative to stayers in the Top 25 US departments. ${ }^{14}$ Thus, in most cases brain drained economists_-particularly those working in the Top 25 US departments - are more productive than stayers. On the other hand, the productivity of brain circulation is generally smaller than the productivity of those who remain abroad (see the details in Section SM6).

Thus, as anticipated in "Introduction," these facts justify a scientific policy for attracting foreign talent, minimizing the elite brain drain, and recovering nationals who have earned a Ph.D. or have spent some time abroad. Note that a defense of such a policy is independent of whether brain drained and brain circulation scientists are positively selected relative to stayers and whether brain circulation researchers are negatively selected relative to the nationals that remain working abroad.

To finish this section, recall that, except for the USA, most countries in our dataset are represented by a reduced number of departments. Thus, our data do not allow for a proper country ranking in productivity terms. Nevertheless, a complete description of our sample should include a comparison of the average productivity of those working in any country. In particular, we are interested in learning which countries are equally, more, or less productive than Spain.

The answer is that, after controlling for personal characteristics, the marginal effect of working in Spain is indistinguishable from the effect of working in Australia, France, Belgium, Denmark, and China, and greater than the effect of working in Italy, Mexico, and the brain circulation countries except Israel. However, the effect of working in Spain is smaller than the effect of working in the remaining countries, namely the USA, the UK, Canada, Switzerland, Israel, Germany, Sweden, and Netherlands (Table L in SM6). We conclude that a good performance in geographic mobility patterns is neither a necessary nor a sufficient condition for excellent research performance according to world standards.

\section{Empirical results}

Our empirical strategy can be summarized as follows. We first estimate the probability that an individual selected at random becomes an immigrant as a function of all control variables and a set of 22 country dummies that take the value one for all individuals who work in 2007 in each country and zero otherwise. We then estimate the average probability that individuals working in a given country become immigrants, i.e., the average probability of brain gain in that country. Next, we estimate the probability that an individual selected at random becomes an immigrant as a function of all control variables and a set of 22 country dummies that take the value one for all nationals in each country and zero otherwise. We estimate the average probability that individuals born in a given country become immigrants, i.e., the average probability of brain drain. The net average probability for each country is defined as the difference between the above two average probabilities.

\footnotetext{
14 However, it can be shown that, under certain values of the parameters capturing the utility of being abroad, the cost of moving, and the premium received for remaining in the USA, this is a prediction in an extension of the Hunter et al. (2009) model.
} 
But the key question is the comparison between the marginal effects of working, or being born, in different countries on the probability that an individual becomes an immigrant holding constant the value of other control variables. The former captures the effect of working in 2007 in that country on the probability of becoming an immigrant, i.e., of becoming brain gained, whereas the latter captures the effect of being born in that country on the probability of becoming an immigrant, i.e., of becoming brain drained. Since we are also interested in which of the two effects is greater, we define the net effect of a country as the difference between the two previous country dummy effects.

\subsection{The model}

Let $m_{i}$ be a dummy variable taking the value 1 if the individual $i$ is an immigrant, that is, if $s /$ he works in a different country from where $s /$ he was born, and 0 otherwise. We specify two binary choice models.

Firstly, a model in which the probability that an individual $i$ becomes brain gained, is a function of a set of controls, $X_{i}$, and a set of working country dummy variables where, for each country $j, \mathrm{WC}_{j i}$ takes the value 1 if the individual $i$ works in country $j$ and 0 otherwise. This can be expressed as follows:

$$
\operatorname{Pr}\left(m_{i}=1 \mid X_{i}, \mathrm{WC}_{1 i}, \ldots, \mathrm{WC}_{22 i}\right)=F\left(\beta_{0}+\gamma^{\prime} X_{i}+\sum_{j=1}^{21} \alpha_{j} \mathrm{WC}_{j i}\right),
$$

where $F$ is the standard normal cumulative distribution function.

Secondly, a model in which the probability that an individual becomes brain drained, is a function of the same set of controls and a set of country of origin dummy variables where, for each country $j, \mathrm{OC}_{j i}$ takes the value 1 if the individual $i$ is born in country $j$ and 0 otherwise. This can be expressed as follows:

$$
\operatorname{Pr}\left(m_{i}=1 \mid X_{i}, \mathrm{OC}_{1 i}, \ldots, \mathrm{OC}_{22 i}\right)=F\left(\delta_{0}+\mu^{\prime} X_{i}+\sum_{j=1}^{21} \lambda_{j} \mathrm{OC}_{j i}\right) .
$$

We estimate these models by maximum likelihood and report three types of results. Firstly, we discuss the impact of control variables in terms of the sign and statistical significance of their estimated coefficients. Secondly, we assess the quantitative significance of the effects of country dummies in terms of their marginal effects, evaluated at the mean value of the continuous explanatory variables and at the value 0 of the binary explanatory variables, denoted by $\bar{X}$. In particular, the marginal effect of working in country $s$ on the probability that an individual becomes brain gained is:

$$
\tau_{s}=F\left(\beta_{0}+\gamma^{\prime} \bar{X}+\alpha_{s}\right)-F\left(\beta_{0}+\gamma^{\prime} \bar{X}\right)
$$

Thus, the probability that an individual working in country $s$ is an immigrant changes in $\tau_{s} \times 100$ percentage points with respect to the probability of being an immigrant in 
the countries in the constant. Similarly, the marginal effect of being born in country $s$ on the probability that an individual becomes brain drained is:

$$
\eta_{s}=F\left(\delta_{0}+\mu^{\prime} \bar{X}+\lambda_{s}\right)-F\left(\delta_{0}+\mu^{\prime} \bar{X}\right)
$$

Thus, the probability that an individual being born in country $s$ is an immigrant changes in $\eta_{s} \times 100$ percentage points with respect to the probability of being an immigrant in the countries in the constant. Since we are interested in which of the two effects is larger, we define the net effect of country $s$ as the difference between (6) and (7):

$$
v_{s}=\tau_{s}-\eta_{s} .
$$

We order all countries in terms of $\tau_{s}, \eta_{s}$, and $v_{s}, s=1, \ldots, 22$, and report in each case whether the differences between the marginal effects for Spain and for the other 21 countries are statistically significant.

Finally, we compute the average probability of brain gain for each countrys, defined as:

$$
\Omega_{s}=\frac{1}{N s} \sum_{i=1}^{N s} F\left(\beta_{0}+\gamma^{\prime} X_{i}+\alpha_{s}\right),
$$

where $N s$ is the number of individuals working in country s. Similarly, the average probability of brain drain for each country $s$ is defined as:

$$
\varphi_{s}=\frac{1}{M s} \sum_{i=1}^{M s} F\left(\delta_{0}+\mu^{\prime} X_{i}+\lambda_{s}\right),
$$

where $M s$ is the number of individuals born in country $s$. As indicated in Sect. 3.2, in general, $N s$ will be different from $M s$. Since we are interested in which of the two average probabilities is larger, we define the net average probability in country $s$ is the difference between (6) and (7):

$$
\Delta_{s}=\Omega_{s}-\varphi_{s}
$$

The average estimated probabilities in expressions (6), (7), and (8) are comparable with the unconditional percentages of brain gain, brain drain, and net gain reviewed in Sect. 3. We order all countries in terms of $\Omega_{s}, \varphi_{s}$, and $\Delta_{s}, s=1, \ldots, 22$, and report in each case whether the differences between the Spanish values and the values of these magnitudes for the other 21 countries are statistically significant.

\subsection{Control variables}

There are three types of control variables: personal, departmental, and country characteristics. Among personal characteristics, we have information on demographics, the university where individuals attend graduate school, and individual productivity. 
Among the demographic variables we consider the individuals' age or academic experience, denoted by Exp. To capture nonlinear effects, we use the variables Exp and $(\mathrm{Exp})^{2}$. We also introduce the dummy variable Female that takes the value one if the individual is female. Graduate education is measured by seven dummy variables. Finally, individual productivity is measured by the individual $Q$ index. Given its high skewness, we use the log of this variable.

We control for department effects by the department mean $Q$ index. Finally, Lepori et al. (2015) emphasize that although academics value primarily the quality of prospective institutions, they are also likely to consider the characteristics of the hosting country. Since we expect that the probability that an individual becomes an immigrant is related to the attractiveness of the country of destination, we include the relative GDP per capita, that is, the ratio of the log GDP per capita of the country of destination over the log GDP per capita of the country of origin.

\subsection{Estimation results}

Table $M$ in Appendix in Supplementary Material presents the estimation results without controls. As expected, these unconditional results reproduce the descriptive statistics previously shown. Then, we add a set of controls to analyze to what extent the unconditional results still hold once we account for some individual, departmental, and country characteristics. In other words, we estimate the two models in expressions (1) and (2), one for the 3540 individuals working in 2007 in the 22 sample countries and another one for the 3253 nationals from these countries. The main purpose of this exercise is to obtain the probability of being brain gained or brain drained for individuals with the same value of those characteristics but working or being born in different countries and to see how the set of country dummy "gaps" change as we add the controls.

We are aware of the potential endogeneity of some of these variables, such as the individual and departmental productivity, but we prefer to condition also on them given that we do not focus on the causal effect of productivity. So, in this sense the potential endogeneity problem is less worrisome. Mean values for all controls in both cases are given in Table $\mathrm{N}$ in Appendix in Supplementary Material. Country mean values for Female, Ph.D. dummy variables, and GDP per capita for the two subsets are given in Tables $\mathrm{O}$ and $\mathrm{P}$ in Appendix in Supplementary Material, while the mean $Q$ for all departments in each country is given in Table A in Section SM1 in Supplementary Material.

The estimated coefficients for the two models are presented in Table 3, where the regression constant refers to researchers working in the following brain circulation countries: Greece, Portugal, Turkey, Brazil, Argentina, and Chile. We note that the pseudo- $R^{2}$ values for the two samples are 0.29 and 0.30 , whereas the pseudo- $R^{2}$ values for the probability of becoming brain gained or brain drained depending exclusively on the working country dummy variables are 0.10 in both cases. (Detailed results are available on request.)

As far as the effect of control variables is concerned, in both cases older individuals have a smaller probability of becoming immigrants and at an increasing rate, but gender 
Table 3 Estimated coefficients of the probability of becoming brain gained and brain drained

${ }^{\mathrm{a}}$ Greece, Portugal, Turkey, Brazil, Argentina, and Chile ${ }^{b}$ Dummy variables that take the value one if the individual obtained her Ph.D. at the following places: (i) Harvard and MIT, the two most popular graduate schools in the USA among the economists with at least one publication that work in 2007 in the top 81 Economics departments worldwide according to the Econphd (2004) ranking (Albarrán et al. 2017a); (ii) the next eight, (iii) the next 15, (iv) and the last 27 US economics departments in the dataset (see Table A in Supplementary Material for the specific schools); (v) other US departments; (vi) the UK, Canada, and Australia; (vi) the remaining countries in the European Union after the accession in 2004 (Germany, France, Italy, Spain,

Netherlands, Belgium, Sweden, Denmark, Greece, Portugal, Austria, Finland, and Ireland), as well as Israel, referred to as Other Western, which are in the regressions' constants; and (vii) other countries in the rest of the world. (Individuals without a $\mathrm{Ph} . \mathrm{D}$. are included in the last category.)

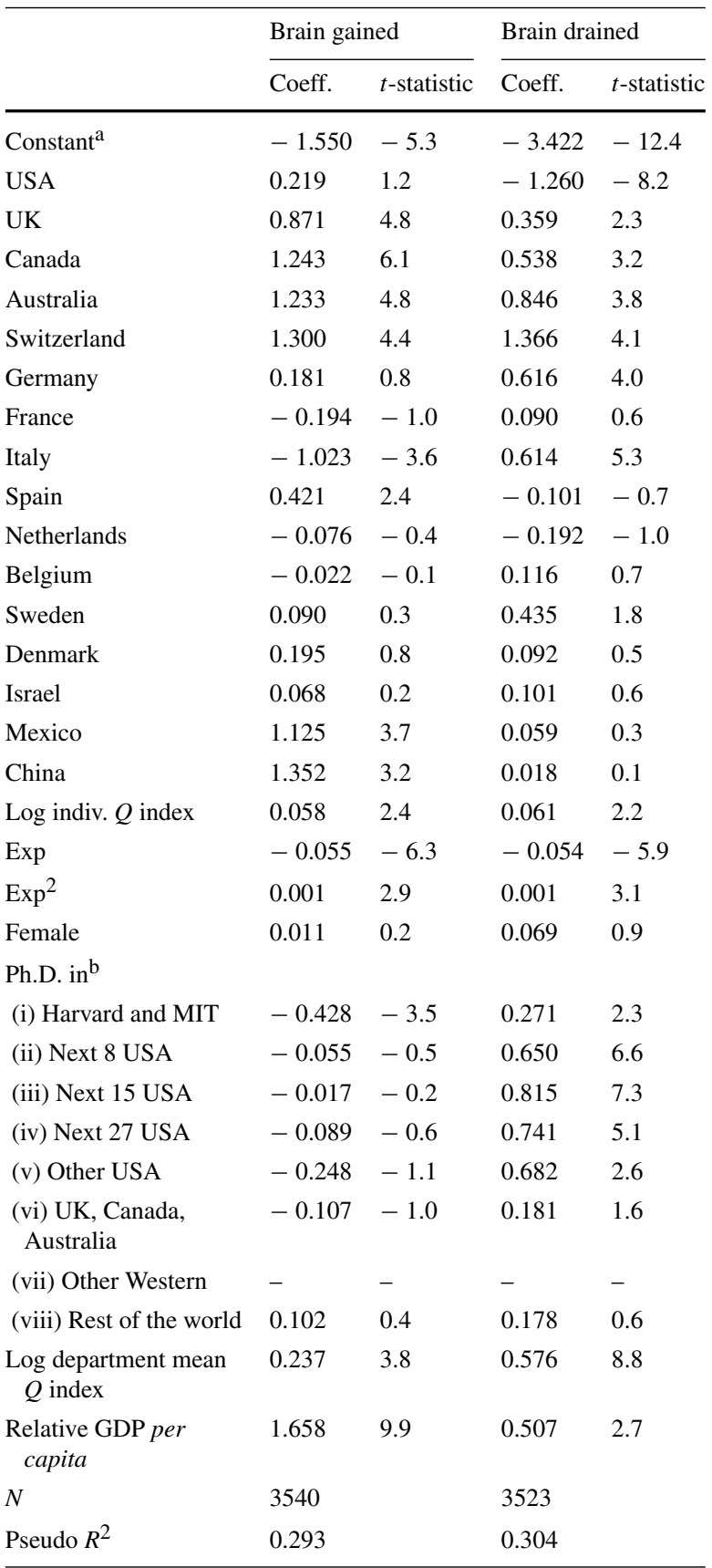


Table 4 Effects of the country dummies on the probability of becoming brain gained

\section{Effects $^{\mathrm{a}}$}

(1)
Differences

relative to Spain ${ }^{\mathrm{b}}$

(2) $p$ values

(3)

\begin{tabular}{|c|c|c|c|c|}
\hline & \multirow{2}{*}{\multicolumn{4}{|c|}{ Greater than Spain }} \\
\hline & & & & \\
\hline & China & 0.501 & 0.350 & 0.005 \\
\hline & Switzerland & 0.484 & 0.333 & 0.000 \\
\hline & Canada & 0.465 & 0.314 & 0.000 \\
\hline & Australia & 0.462 & 0.311 & 0.000 \\
\hline & México & 0.425 & 0.274 & 0.009 \\
\hline & UK & 0.329 & 0.178 & 0.002 \\
\hline & \multicolumn{4}{|l|}{ Equal to Spain } \\
\hline & Spain & 0.151 & - & - \\
\hline & USA & 0.075 & -0.076 & 0.158 \\
\hline & Denmark & 0.067 & -0.084 & 0.275 \\
\hline \multirow{8}{*}{$\begin{array}{l}{ }^{a} \text { Effects of each country dummy } \\
\text { on the probability of becoming } \\
\text { brain gained with respect to the } \\
\text { countries in the constant } \\
\text { (Greece, Portugal, Turkey, } \\
\text { Brazil, Argentina, and Chile) } \\
\text { b Differences between the effect } \\
\text { of each country dummy on the } \\
\text { probability of becoming brain } \\
\text { gained and the effect of the } \\
\text { Spanish dummy }\end{array}$} & Germany & 0.061 & -0.090 & 0.209 \\
\hline & Sweden & 0.030 & -0.121 & 0.206 \\
\hline & Israel & 0.022 & -0.129 & 0.238 \\
\hline & \multicolumn{4}{|c|}{ Smaller than Spain } \\
\hline & Belgium & -0.007 & -0.185 & 0.006 \\
\hline & Netherlands & -0.024 & -0.175 & 0.003 \\
\hline & France & -0.058 & -0.209 & 0.000 \\
\hline & Italy & -0.210 & -0.361 & 0.000 \\
\hline
\end{tabular}

${ }^{a}$ Effects of each country dummy on the probability of becoming brain gained with respect to the countries in the constant (Greece, Portugal, Turkey, Brazil, Argentina, and Chile) ${ }^{\mathrm{b}}$ Differences between the effect of each country dummy on the probability of becoming brain gained and the effect of the Spanish dummy

has no effect. As expected, the probability of attracting a foreigner increases with the individual productivity, the department mean productivity, and the relative GDP per capita of the destination country. It is harder to attract a foreigner who has obtained a Ph.D. from Harvard or MIT, presumably because she becomes brain drained into the USA or returns home as brain circulation, whereas an individual who has obtained a Ph.D. from a US department rather than elsewhere is more likely to become brain drained into the USA or any of the other sample countries.

The key question is how Spain fairs relative to other countries in both models. We begin by considering marginal effects with respect to the countries in the constant, evaluated at the mean value of the continuous control variables and at the value 0 of the binary control variables, i.e., expressions (3) and (4). ${ }^{15}$ The results for the probability of becoming brain gained are given in Table 4. Countries are ordered by the size of country dummy effects in column 1, while column 2 shows the difference between the marginal effect of the corresponding country dummy and the marginal effect of the dummy for Spain, 0.150; thus, for instance, since the marginal effect for China is 0.501 , the difference with respect to Spain is 0.350 . Column 3 presents the $p$ value associated with the null hypothesis that such differences are statistically equal to 0 . It is a Wald type test and the $p$ values are based on the delta method.

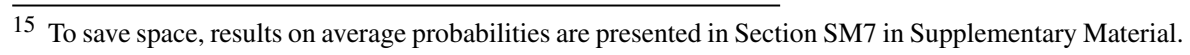


The following two points should be emphasized. Firstly, the effect of working in Spain in 2007 on the probability of being an immigrant is significantly smaller than the effect of working in the four open countries, China, and Mexico. In particular, the probability of being a foreigner if working in China or Mexico is 35 or 27 percentage points greater than if working in Spain. It should be noted that in terms of productivity at the individual and department level as well as graduate education, China is a high performing country, but Mexico is not. On the other hand, the high ranking of Mexico and China is achieved in spite of having a GDP per capita smaller than the one in Spain (Table O in Appendix in Supplementary Material). Secondly, among the four large continental European countries, the effect of working in Spain on the probability of becoming brain gained is indistinguishable from the effect of working in Germany, but greater than the effect of working in France and Italy (by 21 and 36 percentage points greater, respectively).

The results for the probability of becoming brain drained are given in Table 5 . As before, countries are ordered by the size of country dummy effects in column 1, column 2 presents the effect of each country dummy with respect to the dummy for Spain, whereas the $p$ values for such comparison are in column 3. The following three points should be noted. Firstly, the effect of being born in Spain on the probability of becoming brain drained is only greater than the effect of being born in the USA, in particular, 24 percentage points greater as indicated in column 2. Secondly, the only countries for which regression coefficients are significantly positive are the four open countries, plus Germany and Italy. Consequently, the effect on the probability of becoming brain drained of being born in these countries, together with Sweden, is significantly greater (around 27 percentage points) than the effect of being born in Spain, which is negative. Thirdly, the effect of being born in Spain on this probability is indistinguishable from the effect of the remaining 13 countries, including France.

Finally, the main magnitude of interest is the net effect defined in expression (5). The ranking is given in Table 6, and the situation can be summarized as follows. Only China and Mexico are above Spain, whereas only the USA, Canada, the UK and Australia are indistinguishable from this country. Thus, Spain is above the remaining nine countries, including Germany, France, and Italy. We find that the net effect is 27.8, 36.5, and 63.5 percentage points greater for Spain than for Germany, France, and Italy, respectively.

To sum up, descriptive statistics indicate that by 2007 Spain has become an open country (Fig. 1) with a percentage of net gain greater than any other European member in the closed country club (Fig. 2). This has been confirmed after introducing a limited but interesting set of control variables. Country rankings in terms of marginal effects and the net average probability place Spain only below the USA, and above other large and small European countries. Mexico and China also exhibit remarkable performances. ${ }^{16}$

\footnotetext{
16 For completeness, we also estimate the probability of an individual in brain circulation. Results are briefly discussed in Section SM8 in Supplementary Material.
} 
Table 5 Effects of the country dummies on the probability of becoming brain drained
Effects $^{\mathrm{a}}$

(1)
Differences relative to Spain ${ }^{\mathrm{b}}$

(2) $p$ values

(3)

\begin{tabular}{|c|c|c|c|c|}
\hline & \multirow{2}{*}{\multicolumn{4}{|c|}{ Greater than Spain }} \\
\hline & & & & \\
\hline & Switzerland & 0.494 & 0.530 & 0.000 \\
\hline & Australia & 0.328 & 0.364 & 0.000 \\
\hline & Germany & 0.239 & 0.275 & 0.000 \\
\hline & Italy & 0.238 & 0.274 & 0.000 \\
\hline & Canada & 0.208 & 0.244 & 0.000 \\
\hline & Sweden & 0.167 & 0.203 & 0.042 \\
\hline & UK & 0.137 & 0.173 & 0.004 \\
\hline \multirow{11}{*}{$\begin{array}{l}\text { aEffects of each country dummy } \\
\text { on the probability of becoming } \\
\text { brain drained with respect to the } \\
\text { countries in the constant } \\
\text { (Greece, Portugal, Turkey, } \\
\text { Brazil, Argentina, and Chile) } \\
\text { b Differences between the effect } \\
\text { of each country dummy on the } \\
\text { probability of becoming brain } \\
\text { drained and the effect of the } \\
\text { Spanish dummy }\end{array}$} & \multicolumn{4}{|l|}{ Equal to Spain } \\
\hline & Belgium & 0.043 & 0.079 & 0.192 \\
\hline & Israel & 0.037 & 0.073 & 0.292 \\
\hline & Denmark & 0.034 & 0.070 & 0.336 \\
\hline & France & 0.033 & 0.069 & 0.197 \\
\hline & México & 0.021 & 0.057 & 0.546 \\
\hline & China & 0.007 & 0.043 & 0.650 \\
\hline & Spain & -0.036 & - & - \\
\hline & Netherlands & -0.066 & -0.030 & 0.641 \\
\hline & \multicolumn{4}{|c|}{ Smaller than Spain } \\
\hline & USA & -0.281 & -0.245 & 0.000 \\
\hline
\end{tabular}

${ }^{a}$ Effects of each country dummy on the probability of becoming brain drained with respect to the countries in the constant (Greece, Portugal, Turkey, Brazil, Argentina, and Chile) ${ }^{\mathrm{b}}$ Differences between the effect of each country dummy on the probability of becoming brain drained and the effect of the Spanish dummy

\section{Discussion}

How should we interpret these results? If we had all relevant information on the determinants of spatial mobility, country dummy regression coefficients in Eqs. (1) and (2) would not be significant, and country dummy effects in Tables 2, 3, and 4 would be indistinguishable. The probability of becoming brain gained or brain drained would be fully explained by the complete set of control variables. As given in Sect. 5.3, our list of explanatory variables is playing an important control role. ${ }^{17}$ However, our results indicate that there are still significant marginal country effects that should be attributed to unobserved factors. In what follows, we limit our discussion to the Spanish case. (Some brief remarks on Mexico and China are relegated to Section SM10 in Supplementary Material.)

\subsection{Unobserved factors}

There are three possibilities concerning how unobserved variables may affect our results.

\footnotetext{
17 A dramatic example on the brain drain performance in China and Spain before and after introducing control variables is discussed in Section SM9 in Supplementary Material.
} 
Table 6 Net effects of the country dummies a Net effects of each country dummy with respect to the countries in the constant (Greece, Portugal, Turkey, Brazil, Argentina, and Chile) ${ }^{\mathrm{b}}$ Differences between the net effect of each country dummy and the net effect of Spain
Effects $^{\mathrm{a}} \quad$ Differences relative

(1) to Spain $^{\mathrm{b}}$

(2)

\begin{tabular}{lrll}
\hline \multicolumn{2}{l}{ Greater than Spain } & & \\
China & 0.494 & 0.307 & 0.000 \\
México & 0.404 & 0.217 & 0.033 \\
Equal to Spain & & & \\
USA & 0.356 & 0.169 & 0.172 \\
Canada & 0.257 & 0.007 & 0.210 \\
UK & 0.192 & 0.005 & 0.674 \\
Spain & 0.187 & - & - \\
Australia & 0.134 & -0.053 & 0.680 \\
Smaller than Spain & & \\
Netherlands & 0.042 & -0.145 & 0.027 \\
Denmark & 0.033 & -0.154 & 0.086 \\
Switzerland & -0.010 & -0.197 & 0.000 \\
Israel & -0.015 & -0.202 & 0.008 \\
Belgium & -0.050 & -0.237 & 0.001 \\
France & -0.091 & -0.278 & 0.000 \\
Sweden & -0.137 & -0.324 & 0.006 \\
Germany & -0.178 & -0.365 & 0.000 \\
Italy & -0.448 & -0.635 & 0.000 \\
\hline
\end{tabular}

\subsubsection{Unobserved personal characteristics}

The control of personal characteristics - academic age, gender, graduate education, and individual productivity in terms of a weighted index of publications in four journal classes - may have been insufficient. For example, it could be argued that Spaniards are ranked lower than nationals from other countries in terms of unobservable characteristics such as the citation impact of their publications or the subfields to which they belong, so that they are relatively less demanded abroad and must be content working in Spain. In this case, the effect of being born in Spain on the probability of becoming brain drained and the Spanish average probability of brain drain may have been underestimated, and hence, the net marginal effect and the net average probability for Spain may have been biased upwards. This is, indeed, a possibility. However, compared to unobserved department characteristics, we believe that these omissions may at most cause a limited impact.

\subsubsection{Unobserved country characteristics}

There are two cases to be analyzed. We begin with the European closed countries. There are two types of considerations. Firstly, among the variables in Lepori et al. (2015), in this paper we have only controlled for relative GDP per capita because 
we do not have information for the entire sample on other country variables such as the salary and the percentage of people with a higher education, the percentage of GDP devoted to R\&D, or the citation impact of the country's scientific publications. However, Spain does not have an advantage in this respect relative to other European countries that might explain their differences in net effects (details are available on request). Secondly, there are amenities that should be taken into account. For example, it can be argued that the cities where Spanish elite centers are located-Alicante, Barcelona, and Madrid - as well as Spain as a whole, have favorable weather, a lively culture, and good quality of life. ${ }^{18}$ In addition, Spanish is a language worth learning because is widely spoken around the world. Naturally, these unobserved amenities make Spain attractive to foreign scholars in all sciences. However, as discussed in Section 3.4, the unconditional results in Franzoni et al. (2015) indicate that this effect is not present in four scientific fields: biology, chemistry, materials science, and earth and environmental sciences. Therefore, the differences in mobility patterns in economics between Spain and other European countries constitute an exception that requires and ad hoc explanation.

Next, consider the brain circulation countries. In this case, Spain is wealthier than these countries and, among the amenities, it should be emphasized that belonging to the European Union is an important factor contributing to the attractiveness of Spain relative to all non-member countries in this group. Thus, country unobservables might be favoring the situation of Spain relative to the countries with equally remarkable brain gain performances, such as Mexico and China, or the remaining ones capable of attracting mostly brain circulation nationals. This could be particularly the case for Central and South American natives who (except Brazilians) speak Spanish. However, in comparison with other open countries or the Central and South American sample countries (México, Argentina, Chile, and Brazil), the number of Central and South American economists working in Spain is not unduly large. The percentage of these economists relative to the total of foreigners is $8.8 \%$ in Spain, $7.9 \%$ in the USA, Canada, and the UK, and $44 \%$ in the Central and South American countries. ${ }^{19}$

\subsubsection{Unobserved department characteristics}

Although department effects have been partially controlled for by means of the department of destination's average productivity, Spanish centers may be relatively more attractive to both foreigners and natives in unobserved dimensions. In this respect, there is a valuable literature arguing that the research gap between the USA and the rest of the world in any science can be explained by differences in governance and resources (Ali et al. 2007; Aghion et al. 2007, 2010; Bauwens et al. 2008; Veugelers and Van der Ploeg 2008 and, in economics, Drèze and Estevan 2007).

\footnotetext{
18 For the role of factors such as "appeal of the lifestyle or international experience" and "better quality of life," see Franzoni et al. (2015, Table 3 and Fig. 1).

19 Of the 92 Central and South American economists brain drained in any of the sample countries, 72 work in the USA, Canada, or the UK, 11 in Central or South American countries, five in Spain, and four in any of the 14 remaining countries.
} 
Governance Before 1970, only a handful of Spaniards held a foreign Ph.D. and/or had ever written a paper in a peer-reviewed international journal. Since then, an increasing number of Spaniards went abroad to obtain a Ph.D. Out of 164 Spanish economists in our dataset, $41.5 \%$ earned a Ph.D. in the USA, $14.0 \%$ in the UK, and $9.1 \%$ in the rest of the world. Since the mid-1970s, a continuous string of these foreign Ph.Ds. came back to work in Spain. Since the mid 1970s, these "cultural hybrids—nationals socialized in a foreign setting" (Pérez-Díaz 2005)—dominated the economics department at the UAB (Universitat Autònoma of Barcelona) and imposed research excellence as the main aim of academic activity for the first time in Spanish history. This example was followed by the University of Alicante since the mid-1980s. Soon afterward, brain circulation Spaniards led two new research institutions: the IAE (Institut d'Anàlisi Econòmica) and CEMFI (Centro de Estudios Monetarios y Financieros), founded in 1985 and 1987. However, Spanish graduate programs continued to serve the role of preparing students for pursuing a Ph.D. at stronger graduate schools abroad. In brief, from 1970 and 1990, Spain clearly belonged to the brain circulation country group. ${ }^{20}$ The creation of two entirely new university economics departments in 1990, Carlos III in Madrid and Pompeu Fabra in Barcelona, marks the consolidation of a governance model in the six Spanish institutions in our dataset. This model can be summarized in the following three points.

(1) Personnel policies were fundamentally oriented to promoting quality research. Two characteristics stand out (Ruiz-Castillo 2008). Firstly, by avoiding the hiring of graduates from their own doctoral programs, the traditional endogamy characterizing the Spanish university system was drastically reduced. ${ }^{21}$ The recruitment of new faculty was carried out by means of a rigorous selection system open to interested candidates from any other university. ${ }^{22}$ Secondly, the academic staff hired in this way, whose performance is evaluated every 2 years, had a maximum period of 6 years to become tenured faculty members. Among good practices for tenure and promotion decisions, we emphasize the following: Minimum research and teaching excellence standards were clearly established beforehand; letters of recommendation from outside experts were required; merits were evaluated in written reports by ad hoc committees; and final decisions were taken by tenured faculty members in a department vote.

It should be noted that, except for CEMFI, the rest of Spanish institutions in the dataset are public, and their tenured faculty are civil servants. To become a tenured associate or full professor, a candidate must pass a competitive public examination contest-oposiciones-similar to the system followed in other European countries.

\footnotetext{
20 Of the 54 economists working in Spain in 1990, the percentage of stayers, brain circulation, and brain gain is $38.9 \%, 55.5 \%$, and $5.5 \%$, respectively. A distribution very close, for example, to the one in Brazil in $2007(41.3 \%, 54.3 \%$, and $4.2 \%)$ and very different from the one that obtains in Spain at that date: $28.4 \%$, 40.4\%, and 31.2\% (Table B in Section SM4 in Supplementary Material and Fig. 1).

21 As observed in Section SM11 in Supplementary Material, the proportion of inbreeding in Spain in 2007 is smaller than in 14 sample countries: the USA, the four open countries, the seven closed countries, Portugal, and Israel (Table R).

22 The steps included: publishing job vacancies on the Internet; first round candidate selection by an ad hoc committee; interviews with those selected in the job market, which had been held since the mid-1990s at the annual meeting of the Spanish Economic Association and, at least in the case of Carlos III and Pompeu Fabra, in the job market held at the Winter meetings of the American Economic Association; Seminar presentations and, upon hearing department members' opinions, extension of job offers.
} 
Thus, there was a dual system at work: the public system for the country as a whole, and the system described above that operates exclusively within the economics centers in the dataset. However, since the tenure and promotion standards in the latter were much more demanding than in the rest of the system, whenever there was an official vacancy the "internal" candidate had no difficulty filling it against potential rivals; if there were a better candidate willing to work in any of these centers, she would have already been hired there.

2. The four university departments in our dataset had strong Ph.D. programs consisting of 2 years of course study and around 3 years for the writing of a dissertation. Students, all of whom receive financial support during the entire program, were recruited internationally among hundreds of applicants, and the Ph.D. programs in the UAB and the University of Alicante were part of European networks. ${ }^{23}$ Finally, the commitment not to hire their own Ph.Ds. provided incentives to these departments for organizing the best possible program in order to facilitate the placement of their graduate students elsewhere. This also required the organization of a "Spanish" job market that has been working every year since 1995. In contrast, we had to wait until 2018 for the European Economic Association to organize the first version of a European job market for economists.

3. The use of English as a working language was established for the first time in continental Europe in 1966 at CORE (Center for Operations Research and Econometrics) in Leuven, Belgium. Spanish centers followed suit during the 1990s. Seminars and graduate programs in all centers, as well as many disciplines in undergraduate programs at UAB, Carlos III and Pompeu Fabra, were conducted in this language.

Resources Three points should be noted. Firstly, recall that wages have not been controlled for in this study. Anecdotal information suggests that, in purchasing power terms, Spanish salaries for tenured faculty in public institutions in the dataset were equal or below German, French, and Italian ones. ${ }^{24}$ Secondly, in the Spanish case there are two qualifications. (i) There was some leeway concerning what can be paid to young tenure-track candidates. (ii) Contingent on the research (and teaching) trajectory of each faculty member, there were internal incentive systems to assign the teaching load and/or to complement - in a moderate way - the civil servant salaries in public institutions. Having some wage autonomy during the tenure-track period and the annual recognition of research merits were valuable policy options. Thirdly, the

\footnotetext{
${ }^{23}$ ENTER in 1993 originally included the UAB, Toulouse University, University College London, Tilburg University and Mannheim University; afterward the Université Libre de Bruxelles, Stockholm University, and Carlos III University joined the network in 1995, 2003, and 2006, respectively. On the other hand, QED included the University of Alicante, the University of Amsterdam, the University of Bielefeld, the University of Copenhagen, the University Nova of Lisbon, the University Paris I, the University of Venice, and the University of Vienna.

24 Consider, for example, the information on average salaries in academia in US dollars by level of seniority in selected countries and geographical areas in IONOMICS Salary Report 2018 (Graph 5, inomics.com). Relative to Spain, the ratios for junior faculty in Germany, France, and Italy are 1.54, 1.04, and 0.95, respectively. For senior faculty, the ratios are 1.31, 1.31, and 1.05, respectively. Interestingly, these ratios for Central and South America are 1.34 for juniors and 1.01 for seniors. According to this source, average salaries for faculty members in the USA, the UK, or North America and Western Europe are considerably greater than in Spain. We expect these 2018 ratios to be of the same order of magnitude during our sample period.
} 
increase in public resources for higher education in Spain since the mid-1980s in regular university budgets, as well as through competitive national and European Union research grants, made possible to finance, not only Ph.D. programs, but other important academic-related activities, such as travel expenditures, computing facilities, and a rich network of weekly seminars. Sabbaticals and visiting faculty for undergraduate and graduate teaching were also funded.

\subsection{Other factors at work}

To understand how these unobservables at the department level actually affected people's behavior, we must take into account the following two factors. Firstly, in Spain, as in Germany, France, or Italy, for example, academic labor markets in our period of study are fragmented, scarcely mobile and transparent, and dominated by linguistic considerations (Ehrenberg 2003; Avveduto 2005; Musselin 2004, 2005). Recruitment in what Bonaccorsi et al. (2017b) call the Continental Europe model "makes it difficult for universities to enforce a consistent strategy of excellent quality, due to the centralization of main decisions regarding academic staff in terms of legislative and administrative regulation, and the lack of substantive autonomy of departments" (p. 443). Thus, the aggressive recruitment strategy, the meritocratic policy, the minimum degree of inbreeding, the research incentives, the existence of an international Ph.D. program as well as a Spanish job market, and the role of English in daily professional life in our sample Spanish institutions constituted an exception relative to the mass of public centers both in economics and other sciences in Spain and other comparable European countries. The exceptional nature of this experience contributed to its international visibility from its inception.

Secondly, since 1990, the six Spanish centers formed an informal network within which they competed and cooperated. They competed for the best faculty and graduate student talent, as well as for available grants, both within and outside Spain. Thus, they directed their hiring and promotion policy, and they strived to place their Ph.D. students as well as possible, with the aim of improving their reputation-their main weapon in this competitive process. In Aghion et al. (2010), autonomy and competition combined increase universities' productivity. In our case, the virtuous circle of (partial) autonomy and competition improved the performance and the attractiveness of the Spanish centers. At the same time, these centers cooperated in certain dimensions: They shared information and copied organizational solutions adopted by another network member. At any rate, the fact that several centers were able to develop together in a single country reinforced the credibility of the entire experience.

Although nothing like this had taken place in other European countries, it must be recognized that there were very similar experiences in some continental European centers, such as the University of Toulouse that, together with the London School of Economics, has been at the top of all European rankings since 1990. Similarly, human resources policies at the University of Bocconi were based on pursuing research excellence. However, in other German, French, or Italian elite centers, reformist economists had only been able to influence, but not dominate, hiring and promotion policy. Thus, contrary to the Spanish case, good practices in other European countries remain rather 
isolated in a handful of institutions immersed in a traditional public sector system controlled by a relatively large contingent of stayers not particularly interested in meritocratic governance rules.

In this context, Spanish economists with an entrance opportunity into the best Spanish departments easily appreciated the advantages of the new system. This may explain the relatively high proportion of brain circulation in these departments, as well as the relatively low proportion of brain drain among Spanish economists. In turn, foreign faculty members and, above all, new $\mathrm{Ph}$.Ds. from top international graduate programs quickly understood that the Spanish way to implement the Anglo-Saxon department model in a Latin country was credible. Thus, since the early 1990s a considerable number of foreigners decided that, in spite of relatively low wages, working in certain Spanish institutions constituted a good investment in human capital. ${ }^{25}$

To finish this discussion, it must be emphasized that not all was well in Spain. Many of the best foreigners spent only a limited period at Spanish centers before migrating again, or going back to their countries of origin, to profit from better economic and academic conditions. Even some excellent brain circulation Spaniards decided to migrate abroad. Lack of resources has conditioned the ability of Spanish centers to retain much of the best talent that they were able to attract at the beginning of their careers. ${ }^{26}$ Consequently, as observed in Table $S$ in Appendix in Supplementary Material, the percentage of immigrants with less than seven years of experience in Spain is the third largest among the 16 countries with a percentage of brain gain above $14 \%$.

\subsection{After the crisis}

One may wonder how the mobility patterns studied in this paper have been affected by the severity of the 2008 economic recession in Spain. A proper answer requires another paper. Here, we will simply review the faculty composition of the six Spanish centers in the 2018-2019 academic year. As given in Table 7, the total number of individuals has grown from 183 in 2007 to 222 in 2018. The percentage of foreigners in Spain is now $41.3 \%$, well above the $28.4 \%$ in 2007 . These percentages vary from $23 \%$ in the UAB and Alicante, to more than 50\% in IAE and Pompeu Fabra.

The following comments are in order. Firstly, the retirement of most of the 15 Spanish economists around 60 years of age in 2007 has tended to decrease the percentages of stayers and brain circulation. Secondly, a large contingent of young foreigners have kept arriving in recent years. For example, 30 of the 60 brain gain economists at Carlos III and Pompeu Fabra in 2018 (or one third of the total in Spain) are in tenure track

\footnotetext{
25 Recall that the number of foreigners in Spain went from 3 in 1990 to 57 in 2007, with an increase in the percentage of brain gain from 5.5 to $31.1 \%$ (note 20). For the role of non-pecuniary factors for the decisions of migrant scientists on coming to work in their current country of residence, see Stephan and Levin (2001), Sauermann and Roach (2010), Franzoni et al. (2015), Van Bouwel and Veugelers (2014), Lepori et al. (2015), Stephan et al. (2015), Veugelers and Van Bouwel (2015).

26 This coincides with the findings showing that high-skilled workers who have experienced mobility in the past have a higher propensity to move than natives who have never experienced mobility (Kerr and Lincoln 2010), and the findings in Musselin (2004) showing that most post-docs in nuclear physics and biology in France, Germany, and the UK conceive of their foreign experience as a way of improving their chances for recruitment in their own country.
} 
Table 7 Partition of the economists working in 2007 in Spain into stayers brain circulation and brain gain UAB Alicante IAE CEMFI Carlos III Pompeu Total \% \% in $2007^{\mathrm{b}}$ Fabra $^{\mathrm{a}}$

\begin{tabular}{lrrrrrrrrr}
\hline Stayers & 10 & 21 & 1 & 1 & 10 & 12 & 55 & 24.4 & 31.2 \\
$\begin{array}{l}\text { Brain cir- } \\
\text { culation }\end{array}$ & 14 & 9 & 8 & 13 & 17 & 16 & 77 & 34.3 & 40.4 \\
Brain gain & 7 & 9 & 10 & 7 & 23 & 37 & 93 & 41.3 & 28.4 \\
Total & 31 & 39 & 19 & 21 & 50 & 65 & 222 & 100.0 & 100.0 \\
\hline
\end{tabular}

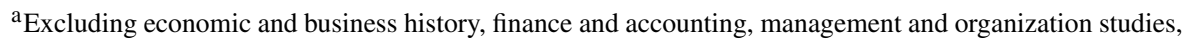
and operations management

${ }^{\mathrm{b}}$ From Table B in Section SM4 in Supplementary Material

and/or have been hired since 2012. The fact that the sum of brain circulation and brain gain has increased from $68.8 \%$ in 2007 to $75.6 \%$ in 2018 indicates that, in spite of the crisis, Spain continues to be an attractive option. Together with the role of the good governance practices emphasized in this paper, it should be noted that national and European funds for research excellence have been exerting a positive impact on Spanish centers since the turn of the century. ${ }^{27} \mathrm{An}$ analysis of brain drain patterns and a comparison with other countries are beyond the scope of this paper.

\section{Conclusions}

In this paper, we have presented some evidence on geographic mobility patterns in elite academic institutions in economics. Conditional on some personal, departmental, and country characteristics, as well as a set of country dummy variables, we have estimated the effect of working in 2007 in a given country on the probability of becoming brain gained, and the effect of being born in a given country on the probability of becoming brain drained. Then, we have also estimated the net effect of each country dummy, defined as the difference between the previous two.

Collecting information on a selection of the best institutions and their faculties using international rankings as well as department and personal Web pages is a difficult job. Thus, our department selection is debatable; the listing of economists in each department might not accurately reflect the roster of full-time researchers in each case, and the information on personal characteristics and publications might be subject to measurement error. We are fully aware that the interest of our results is conditioned by the shortcomings of our dataset. However, in a context of scant information on comparable mobility patterns across countries, we have argued that our data on the brain gain, brain circulation, and brain drain phenomena are of good quality. Moreover, our correlation results on productivity comparisons justify a scientific policy for attracting foreign talent, minimizing brain drain, and promoting brain circulation.

27 In 2018, a total of 56 individuals enjoy special fellowships: 26 from Spanish programs (8 Ramón y Cajal, 8 Maria de Maeztu, 6 Juan de la Cierva, and 4 from other non-profit institutions), 11 ICREA fellowships in Catalunya, and 19 from European sources (15 from the European Research Council, and 4 Marie Curie). In addition, the Catalan institutions (through the Barcelona Graduate School) enjoy the Severo Ochoa grant. 
It can be observed that, until 1990, Spain can be characterized as a brain circulation country where promising B.As. earn a Ph.D. abroad and then come back to work to their country of origin. Italy, Greece, Portugal, Turkey, Brazil, Argentina, and Chile are the countries in our dataset exhibiting this pattern. From 1990 until 2007, however, Spain has joined the USA, the four open countries-UK, Canada, Australia, and Switzerland-and Mexico and China in their ability to attract a sizable proportion of foreigners. In addition, many Spaniards earning a $\mathrm{Ph} . \mathrm{D}$. abroad have returned home, thus reducing the brain drain flow. Differences in the patterns of brain gain, brain circulation, and brain drain between Spain and comparable European countries, i.e., Germany, France, and Italy, are maintained after the introduction of control variables.

How can these mobility patterns be explained? We have suggested an interpretation along the following lines. Against all odds, in the midst of a public system with fixed salaries for tenured positions, coalitions of brain circulation economists in the six Spanish centers in our dataset have autonomously changed the governance of their working places by introducing a rigorous merit system, international Ph.D. programs, and the use of English as a working language. Meanwhile, in the rest of continental Europe there were excellent but isolated comparable experiences. Although we are not well informed on the details, in countries like Germany, France, and Italy the governance of economics departments remained, by and large, unchanged during the period of study. We have argued that the combination of such governance differences with the availability of resources to finance certain strategic research needs has made possible the appearance of a relatively large brain gain and a relatively small brain drain in Spain.

In the search for an explanation of the relatively poor performance of continental Europe in life science, information science, and materials science, Bonaccorsi (2007) has proposed a shift of attention from science policy to scientific institutions: "This is not to say that policies do not matter, but rather that we should consider to what extent their impact may be neutralized by existing institutional features" (p. 311). In this context, the limitations of the dataset and the lack of variables capturing governance characteristics render our results and their interpretation merely suggestive. Nevertheless, they are important because it indicates that, even in the absence of an official policy at the university or the national level and in the presence of relatively low wages, changing the rules at the institution level in an isolated discipline matters by affecting brain gain, brain circulation, and brain drain mobility patterns.

However, lack of resources for retaining some of the best foreigners - and even nationals - has given rise to a second type of brain circulation. Since 1990, Ph.Ds. from top international graduate programs have come to Spain to start their careers before leaving again to their own or other countries. So far, those who had left have been replaced by the next cohort. However, we should note that the results reviewed in this paper favoring Spanish centers in economics are the consequence of favorable circumstances. As indicated in Ruiz-Castillo (2008), ceteris paribus, when the rest of the European countries loosen the reins, establish a higher level of competition in their university systems and design their incentive schemes so as to promote quality research, with the current real salaries in Spain it will be difficult for the most prestigious Spanish institutions to maintain their current attractiveness and hence to emulate the best centers in the rest of the world. 
Acknowledgements Carrasco and Ruiz-Castillo acknowledge financial support from the Spanish MEC (Ministerio de Economía y Competitividad) through Grants No. ECO2015-65204-P and ECO2014-55953-P, respectively, as well as Grants MDM 2014-0431 from the MEC, and MadEco-CM (S2015/HUM-3444) from the Comunidad Autónoma de Madrid to their economics department. Research assistantships by Fernando Gutierrez del Arroyo, Pedro Henrique Sant'Anna, Ana Moreno, and Carlos Berganza are deeply appreciated. Comments from Pedro Albarrán, César Alonso, Salvador Barberá, Olympia Bover, Marco Celentani, Jesús Fernández-Huertas, Jesús Gonzalo, and Matthias Kredler are gratefully acknowledged. Suggestions from two referees and the editor greatly improved the original version. All remaining shortcomings are the authors' sole responsibility.

Open Access This article is distributed under the terms of the Creative Commons Attribution 4.0 International License (http://creativecommons.org/licenses/by/4.0/), which permits unrestricted use, distribution, and reproduction in any medium, provided you give appropriate credit to the original author(s) and the source, provide a link to the Creative Commons license, and indicate if changes were made.

\section{References}

Aghion P, Dewatripont M, Hoxby C, Mas-Colell A, Sapir A (2007) Why reform Europe's universities?. Bruegel Policy Brief, Issue 2007/04

Aghion P, Dewatripont M, Hoxby C, Mas-Colell A, Sapir A (2010) The governance and performance of universities: evidence from Europe and the US. Econ Policy 25:7-59

Albarrán P, Crespo J, Ortuño I, Ruiz-Castillo J (2010) A comparison of the scientific performance of the U.S. and Europe at the turn of the 21st Century. Scientometrics 85:329-344

Albarrán P, Ortuño I, Ruiz-Castillo J (2011) High- and low-impact citation measures: empirical applications. J Informetr 5:122-145

Albarrán P, Carrasco R, Ruiz-Castillo J (2014) The elite in economics. Working paper 14-14, Universidad Carlos III

Albarrán P, Carrasco R, Ruiz-Castillo J (2017a) Geographic mobility and research productivity in a selection of top world economics departments. Scientometrics 111:241-265

Albarrán P, Carrasco R, Ruiz-Castillo J (2017b) Are migrants more productive than stayers? some evidence from a set of highly productive academic economists. Econ Inq 55:1308-1323

Ali S, Carden G, Culling B, Hunter R, Oswald A, Owen N, Ralsmark H, Snodgrass N (2007) Elite scientists and the global brain drain. Working economic research papers, number 825, University of Warwick

Avveduto S (2005) International mobility of scientists and engineer: a study of brain drain and obstacles to mobility. In: Gabbaldon T, Horta H, Meyer DM, Pereira JB (eds) Career, path and mobility of researchers in Europe. Culliver Verlag, Göttingen, pp 16-21

Basu A (2006) Using ISI's 'Highly cited researchers' to obtain a country level indicator of citation excellence. Scientometrics 68:361-375

Batty M (2003) The geography of scientific citation. Environ Plan A 35:761-765

Bauwens L, Mion G, Thisse J-F (2008) The resistible decline of European science. Revision of CORE DP 2003/11

Bonaccorsi A (2007) Explaining poor performance of European science: institutions versus policies. Sci Public Policy 34:303-316

Bonaccorsi A, Cicero T, Haddawy P, Hassan S (2017a) Explaining the transatlantic gap in research excellence. Scientometrics 110:217-241

Bonaccorsi A, Haddawy P, Cicero T, Hassan S (2017b) The solitude of stars. An analysis of the distributed excellence model of European universities. J Informetr 11:435-454

Borjas G (1999) The economic analysis of immigration. In: Ashenfelter O, Card D (eds) Handbook of labor economics. Elsevier, Amsterdam

Carrasco R, Ruiz-Castillo J (2014) The evolution of the scientific productivity of highly productive economists. Econ Inq 52:1-16

Doquier F, Rapoport H (2012) Globalization, brain drain, and development. J Econ Lit 50:681-730

Dosi G, Llerena P, Sylos Labini M (2006) The relationship between science, technologies, and their industrial exploitation: an illustration through the myths and realities of the so-called 'European Paradox'. Res Policy 35:1450-1464 
Drèze J, Estevan F (2007) Research and higher education in economics: can we deliver the Lisbon objectives? J Eur Econ Assoc 5:271-304

Econphd.net rankings (2004). http://econphd.econwiki.com/rank/rallec.htm

Ehrenberg RG (2003) Studying ourselves: the academic labor market. J Labor Econ 21:267-288

Franzoni C, Scellato G, Stephan P (2014) The movers' advantage: the superior performance of migrant scientists. Econ Lett 112:89-93

Franzoni C, Scellato G, Stephan P (2015) International mobility of research scientists: lessons from GlobSci. In: Geuna A (ed) Global mobility of research scientists: the economics of who goes where and why. Academic Press, London

Freeman R (2010) Globalization of scientific and engineering talent: internationalization of students, workers, and ideas and the world economy. Econ Innov New Technol 19:393-406

Freeman R, Huang W (2015) China's 'GreatLeap Forward' in science and engineering. In: Geuna A (ed) Global mobility of research scientists: the economics of who goes where and why. Academic Press, London

Frey B, Eichenberger R (1993) American and European economics and economists. J Econ Perspect 7:185-193

Geuna A (ed) (2015) Global mobility of research scientists: the economics of who goes where and why. Academic Press, London

Herranz N, Ruiz-Castillo J (2013) The end of the 'European paradox'. Scientometrics 95:453-464

Hunter R, Oswald A, Charlton B (2009) The elite brain drain. Econ J 119:F231-F251

Jacob M, Meek VL (2013) Scientific mobility and international research networks: trends and policy tools for promoting research excellence and capacity building. Stud High Educ 38:331-344

Jones B (2008) The knowledge trap: human capital and development reconsidered. NBER working paper no w14138

Kalaitzidakis P, Mamuneas T, Stengos T (2003) Rankings of academic journals and institutions in economics. J Eur Econ Assoc 1:1346-1366

Kerr WR, Lincoln WF (2010) The supply side of innovation: H-1B visa reforms and U.S. ethnic invention. J Labor Econ 28:473-508

Laudel G (2003) Studying the brain drain: can bibliometric methods help? Scientometrics 57:215-237

Laudel G (2005) Migration currents among the scientific elite. Minerva 43:377-395

Lepori B, Seeber M, Bonaccorsi A (2015) Competition for talent. Country and organization-level effects in the internationalization of European higher education institutions. Res Policy 44:789-802

McDowell J, Singell L (2000) Productivity of highly skilled immigrants: economists in the postwar period. Econ Inq 38:672-684

Musselin C (2004) Towards a European academic labor market? Some lessons drawn from empirical studies on academic mobility. High Educ 48:55-78

Musselin C (2005) European academic labor markets in transition. High Educ 49:135-154

OECD (2008) The global competition for talent. Mobility of the highly skilled. OECD, Paris

Panaretos J, Malesios C (2012) Influential mathematicians: birth, education, and affiliation. Not AMS 59:274-286

Parey M, Ruhose J, Waldinger F, Netz N (2017) The selection of high-skilled migrants. Rev Econ Stat 99:776-792

Parker JN, Lortie C, Allesina S (2010) Characterizing a scientific elite: the social characteristics of the most highly cited scientists in environmental science and ecology. Scientometrics 85:129-143

Pérez-Díaz V (2005) La crisis endémica de la Universidad española. Claves de razón práctica 158:38-43

Portes R (1987) Economics in Europe. Eur Econ Rev 31:1329-1340

Rodriguez-Navarro A (2016) Research assessment based on infrequent achievements: a comparison of the United States and Europe in terms of highly cited papers and Nobel Prizes. J Assoc Inf Sci Technol 67:731-746

Rodriguez-Navarro A, Brito R (2018) Technological research in the EU is less efficient than the world average. EU research policy risks Europeans' future. J Informetr 12:718-731

Rodriguez-Navarro A, Narin F (2018) European paradox or delusion-are European science and economy outdated? Sci Public Policy 45:14-23

Ruiz-Castillo J (2008) Economics research in Spain during the 1990s: a literature review. Span Econ Rev 10:221-249

Sauermann H, Roach M (2010) A taste for science? Ph.D. scientists' academic orientation and self-selection into research careers in industry. Res Policy 39:422-434 
Scellato G, Franzoni C, Stephan P (2015) Migrant scientists and international networks. Res Policy 44:108-120

Stark O (2005) The new economics of brain drain. World Econ 6:137-140

Stephan P (2012) How economics shapes science. Harvard University Press, Cambridge, MA

Stephan P, Levin S (2001) Exceptional contributions to U.S. science by the foreign-born and foreign educated. Popul Res Policy Rev 20:59-79

Stephan P, Franzoni C, Scellato G (2015) International competition for Ph.Ds. and postdoctoral scholars: what does (and does not) matter. In: Kerr W, Lerner J, Stern S (eds) Innovation, policy, and the economy, vol 15. MIT Press, Cambridge

Van Bouwel L, Veugelers R (2014) An 'elite brain drain': are foreign top Ph.Ds. in the U.S. less likely to return home? In: Uebelmesser S, Gérard M (eds) Cross border mobility of students and researchers. MIT Press, Cambridge

Velema T (2012) The contingent nature of brain gain and brain circulation: their foreign context and the impact of return scientists on the scientific community in their country of origin. Scientometrics 93:893-913

Veugelers R, Van der Ploeg F (2008) Reforming European universities: scope for an evidence-based process. CESIFO working paper no 229

Veugelers R, Van Bouwel L (2015) Destinations of mobile European researchers: Europe versus the United States. In: Geuna A (ed) Global mobility of research scientists: the economics of who goes where and why. Academic Press, London

Publisher's Note Springer Nature remains neutral with regard to jurisdictional claims in published maps and institutional affiliations. 